\title{
Masonry walls with a multi-layer bed joint subjected to in-plane cyclic loading: An experimental investigation
}

\author{
Miloš Petrovića ${ }^{\mathrm{a}}$, Nebojša Mojsilovića a $^{*}$, Božidar Stojadinovića
}

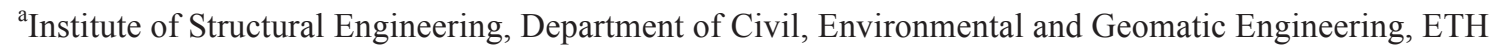
Zurich, 8093, Switzerland.

*Corresponding author. Tel.: +41446333763. E-mail address: mojsilovic@ibk.baug.ethz.ch (N. Mojsilović)

\begin{abstract}
A series of static-cyclic shear tests on full-scale unreinforced masonry (URM) walls with multi-layer bed joints have been performed within a research project on the seismic behaviour of unreinforced masonry walls with soft layer membrane placed in the bed joint to induce sliding. Walls were made using typical perforated Swiss clay blocks and standard cement mortar and the so-called multi-layer bottom bed joints, which comprise a core soft layer protected by two layers of extruded elastomer and placed in the middle of mortar joint. The preliminary testing phase was aimed at choosing the most suitable core soft layer type among the four types considered (rubber granulate, cork, cork-rubber granulate and bitumen). The main testing phase comprised five tests on storey-high URM specimens with rubber granulate core soft layers performed to investigate the influence of the size, the pre-compression level and the aspect ratio on the seismic behaviour of URM walls with a multi-layer bed joint. Sliding occurred in all tested specimens. However, the final failure mode as well as the displacement capacity of test specimens were governed by the extent of shear and tensile (vertical) cracks that developed from the bottom brick course. The response of specimens can be interpreted using a multilinear horizontal forcedisplacement response idealization, whose parameters can be estimated using the proposed equations.
\end{abstract}

\section{Keywords:}

Bitumen, cork, cork-rubber granulate, extruded elastomer, multi-layer bed joint, rubber granulate, shear behaviour, sliding, static-cyclic shear, unreinforced masonry.

\section{Introduction}

Due to their quasi-brittle behaviour, URM structures do not perform well in earthquakes.

Consequently, they usually account for the majority of damage, causing the most fatalities and present the biggest obstacle to the post-earthquake recovery of communities. Such a risk posed by quasi-brittle structures exposed to seismic hazard has been recognized since ancient 
times. Strategies to mitigate this risk are almost as old as engineered construction itself. Sliding on a horizontal surface comprised of superimposed layers of sand and clay is a seismic response mechanism utilized by Japanese builders to protect the 1000-year old Sanjusangen-do Buddhist Temple in Kyoto (Ueda et al. [1]). Sliding was also documented as the primary mechanism that significantly reduced building damage in earthquakes in Assam, India that occurred between 1897 and 1950 (Joshi [2]). Further, sliding was proposed as an effective way to mitigate the seismic damage in unreinforced masonry (URM) structures by Arya et al. [3]. The authors introduced a sliding surface between the foundation beams and bond beams that support the masonry walls by breaking the bond by applying either a polyethylene membrane or they used motor oil. Further, other sliding materials, such as sand, grease, Teflon, graphite and geotextile/smooth marble, were investigated, see Qamaruddin et al. [4], Lou et al. [5], Nikolic-Brzev and Arya [6], Nanda et al. [7] and [8]. A review of previous research on engineered and non-engineered sliding joints enabling friction-slide behaviour and on the dynamics of masonry structures with such joints, can be found in Petrović et al. [9].

The central idea of the current research project is to modify the seismic response of individual structural masonry walls by placing engineered deformable layers (soft layers) at the bottom of such masonry walls. Such layers, mainly based on rubber, bitumen, cork or polyvinylchloride (PVC), have already been used in Swiss URM construction. However, the purpose of implementing such layers is mainly unrelated to seismic actions. Soft layers are used to provide a moisture barrier in the form of a damp-proof course (DPC) membrane, to ensure sound insulation or to accommodate short- or long-term differential movements between the walls and floor constructions. Results from the preliminary research on masonry elements with rubber granulate and elastomer soft layers, e.g. Mojsilović et al. [10] and Vögeli et al. [11], indicated that the presence of such layers in the mortar bed joint can significantly alter the mechanical characteristics of URM walls by creating a sliding plane, 
which, in turn, could influence the seismic response of the entire structure. Rubber granulate soft layers were in some cases heavily damaged during the sliding, whereas the elastomer layers were found to be significantly more durable. Recently, as a part of the presented research project, several series of monotonic and quasi-static cyclic, displacement controlled tests were performed on masonry triplets with a multi-layer bed joint, see Mojsilović et al. [12]. The so-called multi-layer bed joint consisted of a core soft layer (rubber granulate, cork, cork-rubber granulate, bitumen and PVC based membranes were used) which, in order to reduce the damage caused by cyclic loading, was protected by two layers of elastomer, and placed in the middle of the mortar bed joint. Results indicated that multi-layer bed joints with adequate material properties could change the typical brittle shear response of masonry to a more desirable quasi-ductile one. Further, based on the observed hysteretic behaviour, considerable energy dissipation can be achieved in masonry structures with multi-layer bed joints. Such behaviour is desirable for enhanced seismic performance. Furthermore, findings indicated that the loading speed had a considerable influence on the overall behaviour of masonry with a multi-layer bed joint, and especially on the friction coefficient and thus on the shear strength of such bed joints. Similar findings were reported by Trajkovski et al. [13], where it was found that the loading speed affected the shear characteristics of masonry triplets with bitumen- and polyester-based DPCs soft layers placed in bed joints. In addition, it was shown in [12] that the friction coefficient is also a function of the normal pressure (precompression) acting at the interface where the sliding occurs. Having this in mind, it appears that the loading speed and pre-compression are the important parameters for the proper assessment of the horizontal force-deformation characteristics of masonry multi-layer bed joints during sliding.

This paper presents and discusses the test results obtained by performing a series of static-cyclic shear tests on full-scale URM walls with a multi-layer bed joint. A total of 9 walls were tested in two phases. The first (preliminary) testing phase allowed the most 
suitable core soft layer type to be chosen from the four types investigated. Results from the second (main) phase enabled an analysis of the influence of the pre-compression level, aspect ratio and size on the seismic behaviour of URM walls with a multi-layer bed joint. Besides the conventional bilinear, an extended, multilinear horizontal force-displacement response idealization is proposed, together with the equations to determine its parameters (e.g. stiffness and ultimate horizontal force). Finally, a set of conclusions as well recommendations for future work are given.

\section{Test programme and masonry materials}

In order to gain additional insight into the behaviour of large masonry elements with a multilayer bed joint, nine static-cyclic tests were performed in two phases. Table 1 summarizes the test programme, where $l_{w}, h_{w}$ and $t_{w}$ are the length, height and thickness of the specimens (see Fig. 1), $t_{c s l}$ is the core soft layer thickness, $f_{x}$ is the mean compressive strength of the masonry perpendicular to the bed joints, and $\sigma_{p c}$ is the pre-compression stress computed with reference to the nominal wall cross section area $A_{w}=l_{w} \cdot t_{w}$. All walls were tested under fixed-end boundary conditions. Within the first phase of the experimental programme and according to findings from shear tests on masonry triplets [12], four different core soft layer types, namely rubber granulate, cork-rubber granulate, cork and bitumen, were tested. The objectives of the preliminary phase were to determine the most promising type of core soft layer for the main testing phase, and to verify the applied vertical pre-compression levels and the measurement system. Four static-cyclic tests on $1600 \mathrm{~mm}$ high and $1500 \mathrm{~mm}$ long, full-scale URM walls were performed. The preliminary results of the first phase have already been reported, see Petrović et al. [14], and are summarized in section 4.1.

The main phase comprised another five tests on large, storey-high walls with a multilayer bed joint. A rubber granulate soft layer was chosen as a core layer based on the overall behaviour and performance exhibited during the preliminary testing phase, discussed in 
section 4.1. Comparison of the tests results with the results of the test on Specimen Z1, chosen as the reference specimen, enabled the investigation of the influence of the pre-compression level (Specimens Z2 and Z3) and the aspect ratio (Specimens Z5 and Z6) on the seismic behaviour of URM walls with a multi-layer bed joint. Moreover, the results obtained from the preliminary and the main test phases allowed for an investigation of the size effect. Note that specimen designation Z4 has been purposely omitted.

Specimens were constructed in running bond with (nominally) $10 \mathrm{~mm}$ thick mortar fully filled bed and head joints. Fig. 1 shows the structure of the multi-layer bed joint, comprising the top and bottom mortar layers, the $2.2 \mathrm{~mm}$ thick protective layers made of extruded elastomer and the core soft layer. Four different types of core soft layers investigated in this study are also shown in Fig. 1. The thickness of the multi-layer elastomer-coreelastomer sandwich, $t_{m l}$, ranged between 6.4 and $7.9 \mathrm{~mm}$ depending on the type of the core soft layer, while the total thicknesses of a multi-layer bed joints (including the two mortar layers) ranged from 15 to $18 \mathrm{~mm}$. The specimens of both test phases were built by experienced bricklayers in separate batches, but with the same materials (except mortar), and were kept in open air in the laboratory for a minimum of 28 days before testing.

Typical Swiss perforated clay blocks, with nominal dimensions of 290 x 150 x 190 $\mathrm{mm}$ and void area of $42 \%$, were used to build the specimens for both testing phases, cf. Fig. 1. The compressive strength of the blocks was determined according to EN 772-1 [15] on a sample of 10 blocks, and was equal to $31.2 \mathrm{MPa}$. The compressive strength of standard cement mortar for each phase was determined by testing the mortar prisms with dimensions of $40 \times 40 \times 160 \mathrm{~mm}$. The prisms were tested according to EN 1015-11 [16] after a curing period of at least 28 days. The mean compressive strengths of $6.9 \mathrm{MPa}$ and $7.9 \mathrm{MPa}$ were determined for the mortar used to prepare the specimens for the first and the second testing phase, respectively. 
The masonry compressive strength perpendicular to the bed joint direction, $f_{x}$, was determined in accordance with the provisions of EN 1052-1 [17]. For each implemented core soft layer three specimens with nominal dimensions of $1000 \times 600 \times 150 \mathrm{~mm}$ were constructed at the same time as the walls for the first testing phase. In addition, three such specimens without layers were constructed and served as a reference. These specimens were subsequently tested in a general-purpose testing machine. The test results, i.e. mean values from three tests conducted, are summarized in Table 2 . This Table also presents the ratio $\beta$ between the strengths of the walls with and without multi-layer bed joint. It can be seen that the influence of a multi-layer bed joint on the masonry compressive strength was not significant. The compressive strength of specimens with rubber granulate core soft layer was reduced by 11\%. More details can be found in Mojsilović et al. [18].

\section{Test set-up, testing procedure and measurements}

The test set-up is shown in Fig. 2. The specimens (1) were built on $350 \mathrm{~mm}$ thick reinforced concrete pedestals (2), which in turn were clamped to the laboratory strong floor (3) by means of post-tensioned steel bars. The horizontal servo-hydraulic actuator (4), connected to the reaction wall (5), was used to apply horizontal displacements to the top of the walls through a stiff horizontal steel loading beam (6). The loading beam was connected to the walls by a layer of mortar (7). The mortar layer also ensured uniform vertical load distribution. The vertical load was applied by means of two servo-hydraulic actuators (8) reacting on the reaction frame (9). In order to prevent any out-of-plane movement of the loading beam, an auxiliary, low friction sliding system (not shown on Fig. 2) was used to guide the web of the loading beam (6) during the tests. For each test, a specimen was first pre-compressed to the designated stress level, simulating the gravity load supported by the wall, and then subjected to the static-cyclic shear load that was applied using computer-controlled displacement steps chosen to have the form of a sinusoidal wave. Each step was repeated three times. All tests 
started with a push cycle (positive horizontal displacement and force). The loading speed was determined by the corresponding target displacement, i.e. the loading speed increased with increasing target displacement. Loading histories used for the preliminary and main testing phase are presented in Table 3, where the target drift ratio is the value of target displacement divided by the specimen's height.

All specimens were tested under fixed-end boundary conditions, i.e. the rotation at the top and the bottom of the specimen was restricted. The fixed-end boundary conditions were ensured by a mixed force-displacement control of the vertical actuators which, besides the role of keeping the pre-compression level constant during the tests, have been used to keep the loading beam horizontal. More detailed information about the test controlling system can be found in Salmanpour et al. [19, 20]. Each test was stopped either due to critical damage conditions or when the response of the specimen was stable (pure sliding) and no difference in response quantities between several consecutive loading history steps was observed.

All measured data were recorded and processed in real time. Apart from the applied vertical and horizontal loads and the displacements of the servo-hydraulic actuators, measurements comprised vertical, horizontal and diagonal deformations of the specimens, cf. Fig. 3. Vertical deformations were measured by means of a pair of potentiometers (POTs), WVN and WVS. Potentiometers WHB, WHM and WHT measured horizontal deformations (WHM was not implemented during the preliminary testing phase). Further, diagonal deformations of the walls were captured using another two POTs, WD1 and WD2. Linear variable differential transformers (LVDTs) NS, MSN, MSS and SS were applied to measure the sliding displacement (slip) of the specimen along the multi-layer bed-joint with respect to the reinforced concrete pedestal. The vertical (uplift) displacement along the multi-layer bedjoint was measured by means of NU1, NU2, SU1 and SU2 (an additional pair was used for the test on the longest specimen, Z6), while LVDTs TSD1-4 were used for measuring the vertical displacements at the top of the specimen. The horizontal displacement of the top of 
the specimen was measured on the North side (WTLaser). Another laser measuring device (CTRLaser) was used to control the horizontal displacement of the loading beam, cf. Fig. 3. The vertical displacement of the loading beam on the North and the South sides was captured by means of NVD and SVD, respectively. These two LVDTs were part of the test controlling system. LVDTs WBSN and WBSS were installed to detect the (possible) slip between the loading beam and the specimen, while the slip between two constituent parts of the loading beam was tracked by means of LVDT PBS. Finally, potentiometers CUN, CUS and CS were installed to monitor the vertical as well the horizontal displacement of the concrete pedestal.

Besides a conventional hard-wired measuring system (LVDTs and POTs), a 2D Digital Image Correlation (DIC) measurement system was used to obtain the information on the deformation field on the surface of a specimen during a test, see Fig. 4. DIC is a noncontact optical system that measures displacements directly by comparing consecutive digital images of the specimen's surface obtained before and after deformation. This measurement system requires a random pattern to be applied on the surface of tested object. More details on the implemented DIC system can be found in Salmanpour et al. [21], and Mojsilović and Salmanpour [22]. The computer used for data acquisition triggered the DIC cameras at the predefined displacement levels in each cycle performed. Figs. 5 and 6 show example of the details of the applied patterns and the evaluated global and local strain fields of specimens WK and Z3.

\section{Test results and specimen behaviour}

The values of the extreme (maximum and minimum) horizontal force, $H_{\max }$ and $H_{\min }$, and horizontal displacement, $d_{\max }$ and $d_{\min }$, recorded during testing are summarized in Table 4. Further, the extreme horizontal displacements in terms of drift ratio $\delta$ (i.e. displacement values normalized by the specimen height), as well as the values of the specimen's initial (tangent) stiffness, $K_{0}$, and displacements $d_{t, \max }$ and $d_{t, \min }$ corresponding to the occurrence of 
significant loss of horizontal force resistance are also reported. The horizontal forcedisplacement response hysteresis curves of the tested specimens are shown in Fig. 7. The deformation value shown in the diagrams is the horizontal displacement of the loading beam, which can be considered as representative of the displacement of the top of the walls, since, in each test, no slip between the loading beam and the wall was recorded. Note the different axis scaling for some of the presented hysteresis curves: this was chosen to present clearly the development of the hysteretic response.

Fig. 8 shows the values of the equivalent viscous damping ratio, $\xi_{\text {eq }}$, used to measure the energy dissipation characteristics. As stated in Chopra [23], the most common method for defining equivalent viscous damping is to equate the energy dissipated in a vibration cycle of the actual structure (the area enclosed by the hysteresis loop) and an equivalent viscous system (a function of the strain energy). The values given are calculated for each first cycle applied and plotted against the corresponding target displacement. Evidently, a welldeveloped sliding response in Specimens Z2, Z1 and WB results in almost ideal elastic-plastic horizontal force-displacement response hysteresis loops (Fig. 7) and very high values of equivalent viscous damping ratios. Somewhat less energy is dissipated when shear and/or flexure of the masonry contributes more to the overall response (e.g. Specimens Z3 and Z5). It should be noted that for calculating the strain energy, the horizontal force values were chosen as $90 \%$ of the maximum horizontal force attained within the cycle considered, since the horizontal force values corresponding to the maximum applied displacement led to an underestimate of the actual strain energy, cf. Fig. 7.

\subsection{Preliminary testing phase}

All specimens tested in the preliminary phase responded quite similarly. Generally, the response was non-linear from the beginning (but more pronounced when the horizontal displacement exceeded $1 \mathrm{~mm}$ ). Subsequently, with increasing deformation the response evolved into an ideal plastic horizontal branch (more pronounced for Specimens WG and 
WB). All specimens exhibited large energy dissipation (Specimens WG and WB to a greater extent, cf. Fig. 8a) and behaved in a quasi-ductile manner. Sudden changes in values of the equivalent viscous damping ratio, and thus the slope change of the lines given in Fig. 8, correspond to the occurrence of significant (shear and/or vertical tensile) cracks. Each test was stopped when critical damage conditions occurred.

The response of all specimens was initially concentrated at the soft layer level (shear deformation of the multi-layer bed joint, cf. Fig. 5c). During the second loading step with the target displacement of $0.8 \mathrm{~mm}$ (corresponding to a horizontal drift ratio of $0.05 \%$ ), sliding at the interface between the core soft layer and the elastomer appeared, see Fig. 9a. As it was in the case for static-cyclic shear tests on masonry triplets with a multi-layer bed joint [12], and in spite of the fact that sliding had already occurred, values of the recorded horizontal force increased as the number of performed cycles increased, cf. Fig. 7. Further sliding motion caused lateral tensile stresses at the bottom brick course of the specimen, which led to vertical tensile cracks in the head joints and eventually to the separation of the head joint mortar from the blocks. Simultaneously with the sliding motion, which amounted to between $60 \%$ and $80 \%$ of the applied horizontal displacement, depending on the displacement step and specimen considered, diagonal shear cracks formed along the bed and head joints (staircaselike cracks) starting from the middle of the wall with subsequent extension through the brick units. The aforementioned tensile cracks in the bottom brick course spread to the upper courses of the wall as the tests progressed and caused the reduction of the effective area of the bottom cross section of the specimen, cf. Fig. 9b and 9c. The level of the reduction of the wall effective area, which in turn depended on the position of the tensile cracks in the bottom brick course and whether or not they subsequently merged with the already formed diagonal shear cracks, determined the subsequent behaviour of the specimen. Moreover, due to the separation of the specimen along the staircase-like cracks into individual parts, another sliding interface between the mortar and the upper elastomer layer of the multi-layer bed joint occurred. 
Specimens WB and WG slid more than Specimens WGK and WK. Nevertheless, shear was finally the common failure mode for all specimens. Fig. 10 shows the final crack patterns of the tested specimens.

\subsection{Main testing phase}

The response of specimens of the main testing phase was initially non-linear, more significantly so after exceeding $0.64 \mathrm{~mm}$ of horizontal displacement $(0.025 \%$ drift ratio). Subsequently, the response evolved into an ideal plastic horizontal branch. Specimens of the main testing phase exhibited a considerable energy dissipation capacity and behaved in a quasi-ductile manner, cf. Fig. 8b. The final crack patterns are shown in Figs. 11 and 12.

Before sliding at the interface between the rubber granulate core soft layer and the elastomer started during the cycle with the target displacement of $1.95 \mathrm{~mm}(0.075 \% \mathrm{drift}$ ratio), regardless of the specimen aspect ratio or the level of pre-compression, the multi-layer bed joint underwent pure shear deformation. Here too, although limited, as indicated from the test on Specimen Z2, the influence of the loading speed on the value of the recorded horizontal force was apparent, cf. Fig. 7. It was observed that, in spite of further increasing the loading speed, over the value of $9.5 \mathrm{~mm} / \mathrm{min}$ (a cycle with the target drift ratio of $0.8 \%$ ), there was no increase of the horizontal force. Sliding measured at the bottom of each wall was around $80 \%$ to $90 \%$ of the applied horizontal displacement. However, except in the case of Specimen Z2, which responded in pure sliding with almost no cracks (cf. Fig. 11), a stable pure sliding response mechanism was interrupted by the appearance of (vertical) tensile cracks at the bottom layer of the bricks. These cracks, as mentioned before, progressed to the upper part of the walls and merged with the already formed diagonal shear cracks causing the reduction of the effective areas of the walls (see Figs. 11 and 12) and thus influenced the subsequent response of the walls. In the case of the Specimen Z1 the sliding continued with minor shear cracks, which formed in the middle of the wall, see Fig. 11. 
With increasing level of pre-compression (Specimen Z3) further sliding response was limited since the remaining effective part of the wall failed in shear (the cycle with the drift ratio of $0.5 \%)$. The wall with the higher aspect ratio (Specimen Z5) also failed in shear, after responding prevalently in sliding, at a horizontal displacement of $7.8 \mathrm{~mm}$ (drift ratio of $0.3 \%$ ). Finally, Specimen Z6 (the $3.6 \mathrm{~m}$ long specimen) behaved similar to the reference wall. However, the sliding response was interrupted by the shear failure of the remaining effective part of the wall. Thereafter, another sliding mechanism was established in the multi-layer bed joint, and the middle part of the wall continued to slide up to the final compressive failure of the bottom brick course (at the horizontal drift ratio of 0.6\%), see Fig. 12.

\section{Horizontal force-deformation response characterization of URM walls with}

\section{multi-layer bed joints}

In the following sections, the behaviour of the tested specimens with a multi-layer bed joint is discussed in terms of the horizontal force resistance and the size effect, horizontal forcedisplacement response stiffness and horizontal displacement capacity. Then, the influence of the core soft layer type, pre-compression level, aspect ratio on the observed response is discussed. Further, the degradation of the implemented soft layers caused by cyclic loading is addressed.

\subsection{Horizontal force resistance and the wall size effect}

The sliding and shear strength of the tested URM walls with multi-layer bed joints can be quantified using the classical Mohr-Coulomb's failure criterion $\tau=c+\sigma_{p c} \cdot \tan \varphi$, where $c$ and $\varphi$ are the cohesion and the angle of internal friction, respectively. The pre-compression stress is $\sigma_{p c}=N / A_{w}$, where $N$ is the vertical pre-compression load of the specimen and $A_{w}=t_{w} \cdot l_{w}$ is the nominal cross section area of the wall. Then, the maximum calculated horizontal force resistance of URM walls with multi-layer bed joints is:

$$
H_{\text {max }, \text { calc }}=A_{w} \cdot\left(c+\sigma_{p c} \cdot \tan \varphi\right)
$$


Using the friction coefficients, $\tan \varphi$, determined from the investigation on masonry triplets with a multi-layer bed joint [12], while neglecting the small cohesion values and taking into account the applied pre-compression stress level, the experimentally obtained values of the maximum horizontal force resistance of specimens of the preliminary testing phase could be predicted well, cf. Table 5. However, the correlation between the experimental and the calculated values of the maximum force resistance of specimens of the main testing phase is not that good. This is, likely, caused by the size effect.

Results obtained by testing Specimens WG and Z1, which had (almost) the same aspect ratio and were tested under the same pre-compression stress level $(10 \%$ of the masonry compressive strength) but have different size allow one to assess the (wall) size effects. Both specimens responded in sliding in the multi-layer bed joint. However, the amount of sliding, expressed as a percentage of the applied wall horizontal displacement, was smaller for Specimen WG, thus indicating a larger contribution of the shear deformation of the masonry. This can be seen by comparing the crack patterns shown in Figs. 9 and 11. Compared to Specimen Z1, Specimen WG exhibited more extensive shear cracks. These cracks governed the specimen behaviour after the reduction of wall effective area occurred. Specimen WG failed in shear at the drift ratio value of $0.8 \%$. On the other hand, Specimen Z1 continued to slide without failing in shear until the test was stopped at the drift ratio of $1.5 \%$. Such behaviour can be attributed to the size effect, i.e. to the ratio between the size of a single brick and the size of a specimen. When this ratio is smaller (for taller specimens with the same aspect ratio), the stress distribution is more uniform and there are fewer cracks. Further, the stiffness of the larger specimen (Z1) is higher than that of the smaller one (WG), the difference being even more pronounced than in the case of similar walls without layers [20].

The effect of wall length on the horizontal force resistance of the specimens is assessed by considering Specimens Z1, Z2 and Z3 that have the same aspect ratio but different pre-compression levels. The shear stress vs. normal stress data for these specimens is 
plotted in Fig. 13a. A line fitted through this data is used to estimate the Mohr-Coulomb failure criterion parameters: an apparent friction coefficient of $\tan \varphi=0.2$ and a corresponding apparent cohesion of $c=0.15 \mathrm{MPa}$. The estimates of the maximum horizontal force resistance of the specimens tested in the main test phase made using these results (instead of those from [12]) in Eq. 1 are listed in Table 5. Evidently, the observed maximum horizontal force resistance of Specimens Z5, Z6 and WG is predicted fairly well, cf. also Fig. 13b. Thus, increasing the size of the specimen, and therefore the length of the multi-layer bed joint, reduces the apparent friction coefficient, while the contribution of the apparent cohesion to the horizontal force resistance rises and cannot be neglected anymore.

\subsection{Stiffness}

The value of elastic horizontal force-displacement response stiffness $K_{e l}$ of a masonry wall can be adequately estimated using the elastic beam theory incorporating both shear and flexure deformation, see e.g. [25]. Vögeli et al. [11] extended the calculation of $K_{e l}$ for the URM walls with a soft layer bed joint, where the additional soft layer shear deformation was considered. The level of pre-compression is considered through the reduction of the thickness of the multi-layer bed joint $\Delta t_{m l}$. Thus, the stiffness of URM walls with a multi-layer bed joints is:

$$
K_{e l}=\frac{G_{m} \cdot A_{w}}{1.2 \cdot h_{w} \cdot\left(1+\alpha^{\prime} \cdot \frac{G_{m}}{E_{m}} \cdot\left(\frac{h_{w}}{l_{w}}\right)^{2}+\frac{\left(t_{m l}-\Delta t_{m l}\right)}{1.2 \cdot h_{w}} \cdot \frac{G_{m}}{G_{m l}}\right)}
$$

where $G_{m}$ and $E_{m}$ denote the shear and the elasticity moduli of masonry, respectively, and $G_{m l}$ denotes the shear modulus of the multi-layer bed joint. The mortar layers of the multilayer bed joint (Fig. 1) are neglected because they are much stiffer than the elastomer and the core soft layers. Typical values of the shear modulus for the masonry are about $2200 \mathrm{MPa}$, while those for the multi-layer bed joint are about 2.6 MPa, three orders of magnitude less. The thickness of the multi-layer bed joint that effectively deforms in shear before sliding 
begins is the original thickness $t_{m l}$ reduced by the amount of axial deformation (flattening) of the multi-layer bed joint due to the pre-compression load, $\Delta t_{m l}$. Values of $\Delta t_{m l}$ measured after applying the vertical pre-compression load for each test are listed in Table 6 . The effect of the axial deformation of the multi-layer bed joint on the stiffness is small: nevertheless, it is considered here for completeness. Coefficient $\alpha$ ' accounts for the boundary conditions of the specimen. It equals to 0.83 for the fixed-end boundary conditions, and 3.33 for the cantilever boundary conditions.

Values of the elastic stiffness of each wall calculated using Eq. 2 are shown in Table 7, while the parameters used for the calculation are summarized in Table 6 . The calculated values of $K_{e l}$ are very well correlated to the measured values of the initial stiffness $K_{0}$, see Fig. 14. It is notable (from Eq. 2) that the walls with multi-layer bed joints deform about 3 times more in the elastic range than the URM walls without such joints. Thus, it is important to account for the shear deformability of the soft layer in multi-layer bed joints and its effect on the stiffness and dynamic characteristics of walls with multi-layer bed joints.

\subsection{Horizontal displacement capacity}

The stiffness of all tested specimens remained close to their initial elastic stiffness until they reached their maximum horizontal force resistance. Then, they deformed (plastically) without an increase in resistance. However, the maximum horizontal displacements achieved during different tests depend on the specimen failure modes (cf. Table 4). Specimens Z1 and Z2 responded in pure sliding along the multi-layer bed joint, cf. Fig. 7 (the former one did so in spite of the reduction of the wall effective area). These two tests were terminated even though the sliding capacity of the multi-layer bed joint was not exhausted. Even though the ultimate horizontal displacement of such walls is large, it is practically limited due to the interaction of the wall with other structural and non-structural components of the building. The ultimate drift ratio limit of $0.8 \%$ [24] to $1 \%$ [26] for the predominantly sliding type of response, is also acceptable for URM walls with multi-layer bed joints. Other specimens, after developing 
some sliding in the multi-layer bed joints, failed in shear either before (Specimens WGK, WK and Z5) or after the wall effective cross section areas were reduced do to separation into individual segments along the shear cracks (Specimens WG, WB, Z3 and Z6). The specimens in the latter group exhibited a fairly sudden drop in horizontal force resistance. The displacements $d_{t, \max }$ and $d_{t, \min }$ corresponding to such sudden loss of resistance in the push and pull test directions are listed in Table 4.

\subsection{Horizontal force-displacement response idealization}

In general, the response of URM walls subjected to cyclic shear is non-linear and depends on several parameters, such as the pre-compression level, the wall aspect ratio and the wall boundary conditions. Moreover, a cycling-induced reduction of the strength and the stiffness of masonry wall is obvious. Usually, the horizontal force-displacement response hysteresis of a masonry wall under reversed cyclic loading is simplified by idealizing the envelope of the hysteresis using a bilinear (linear-elastic ideal-plastic) or multi-linear relations. Different approaches to determine this bilinear idealization, i.e. its parameters (the effective stiffness, ultimate displacement and the ultimate horizontal force resistance), could be found in the literature. For example, Tomaževič [25] calculates the ultimate horizontal force resistance from the condition that the areas (i.e. the work) under the actual cyclic response envelope and its idealization are the same. Further, based on numerous tests, the ultimate horizontal force resistance assigned to the idealized response, $H_{u}$, is approximately equal to $90 \%$ of the maximum horizontal force resistance attained during the cyclic tests $\left(\max \left\{H_{\max },\left|-H_{\min }\right|\right\}\right.$ in Table 4). However, the force-deformation response curves obtained from the present tests do not allow for a straight-forward application of the procedure described above. As mentioned before, the point where the maximum horizontal force is attained is not the same as the point of the maximum horizontal displacement due to the change of the velocity during a sine-wave loading cycle. 
Therefore, an idealization of the envelope of the horizontal force-displacement hysteretic response of a URM wall with a multi-layer bed joint is proposed in Fig. 15(a). The value of the ultimate horizontal force resistance is $H_{u}=0.9 \cdot H_{\max }$, calc, where $H_{\max , \text { calc }}$ is computed using Eq. 1. The elastic stiffness $K_{e l}$ is computed using Eq. 2. Consequently, the displacement $d_{y}$ when the response of a URM wall with a multi-layer bed joint ceases to be elastic (i.e. apparent yield displacement), can be computed (Table 7). Past displacement $d_{y}$ the response is assumed to be plastic, with the horizontal force resistance equal to $H_{u}$, until displacement $d_{t}$ is attained, when a sudden drop of horizontal force resistance occurs. The ratios of the observed displacements $d_{t}$ (Table 4) and the computed values of displacement $d_{y}$, shown in Table 7 are consistently about 6.0 for specimens that exhibited shear failure. The ultimate displacements $d_{u}$ of the specimens that separated into individual parts (WG, WB, Z3 and Z6) was approximately 10 times $d_{y}$, while that of the specimens that did not separate (WGK, WK and Z5) was less than $10 d_{y}$ (Table 7). The remaining horizontal force resistance, $H_{r}$, of the specimens with a rubber granulate soft layer (WG, Z3 and Z6) varies, but is larger than $0.6 H_{u}$. An idealized envelope of the hysteretic horizontal force-displacement response of Specimen Z6 in the first quadrant computed using the procedure stated above is shown in Fig. 16(a).

The specimens whose response was dominated by sliding (Z1 and Z2) did not experience a drop in strength. The idealization of their horizontal force-displacement response is simpler, elastic-plastic, as shown in Fig. 15(b). Their ultimate displacement is limited by the interaction with other structural and non-structural elements of the building and is set to a drift value of $1 \%$ (Table 7). An idealized envelope of the hysteretic horizontal forcedisplacement response of Specimen Z1 in the first quadrant computed using the procedure stated above is shown in Fig. 16(b).

The idealized horizontal force-displacement response envelopes for all tested specimens are shown in Fig. 17. It should be noted here that a similar general horizontal 
force-deformation response envelope for URM walls is suggested by Figure 7-1 of FEMA 356 [24]. The parameters of this envelope are specified in FEMA-356 Table 7-4. Note that the FEMA-356 force-deformation envelope does not apply for Specimens WB, Z1, Z2 and Z5. All of these specimens responded in pure sliding on the multi-layer bed joint. Thus, they do not exhibit a drop in horizontal resistance and their displacement capacity is limited by other elements of the structure.

\subsection{Influence of the pre-compression level}

The influence of the pre-compression level can be assessed by comparing the results obtained for Specimens Z1, Z2 and Z3. The results indicate that as the level of pre-compression increased, the stiffness, the apparent yield displacement and the horizontal force resistance increased, cf. Tables 4 and 7. Further, an increase of the level of pre-compression influenced the reduction of the wall effective area, cf. Fig. 11. Specimens Z1 and Z3 (tested under the pre-compression level of $0.52 \mathrm{MPa}$ and $1.04 \mathrm{MPa}$, respectively) underwent such a reduction during cycles with the target drift ratio of $0.3 \%$ and $0.2 \%$, respectively. In the case of Specimen Z3 the horizontal force resistance degraded, while such degradation was negligible for Specimen Z1, cf. Fig. 7. Thereafter, the (remaining) effective parts of Specimens Z1 and Z3 continued to respond in sliding. However, Specimen Z3 failed in shear at a drift ratio of $0.5 \%$, while the sliding mechanism of Specimen $\mathrm{Z} 1$ was stable until the test was interrupted at a drift ratio of $1.5 \%$. Specimen Z2, tested under the lowest pre-compression level of 0.26 $\mathrm{MPa}$, did not exhibit an effective area reduction and responded steadily in pure sliding (the test was stopped at a drift ratio of $2 \%$ ).

\subsection{Influence of the aspect ratio}

Specimens Z5 and Z6 were tested to investigate the influence of the wall aspect ratio $\left(h_{w} / l_{w}\right)$ on the behaviour by comparing the results obtained with the results of the reference test $\mathrm{Z} 1$, which had aspect ratio of 1 . The test results show that, as found in previous studies on the conventional URM walls (e.g. [20]), the horizontal force resistance and the stiffness increases 
with decreasing aspect ratio. Further, the values of the apparent yield displacement were slightly affected by changing the aspect ratio. In spite of the same initial behaviour, Specimen Z6 developed a $60 \%$ smaller value of horizontal displacement prior to failure compared to Specimen Z1. This was mostly due to the reduction of the wall effective area. Specimen Z5, with the highest aspect ratio, failed in shear during the cycle with the target drift ratio of $0.35 \%$ (about $76 \%$ lower displacement capacity than that of Specimen Z1). Given the above, it can be concluded that either increasing or decreasing the aspect ratio with respect to the reference value of $h_{w} / l_{w}=1$, the displacement capacity of URM walls with a multi-layer bed joint decreases. However, by lowering the aspect ratio, the probability of establishing a new and stable response regime, after the wall effective area is reduced, increases. This could possibly improve the deformation capacity of URM walls with multi-layer bed joints.

\subsection{Influence of the core soft layer type}

Results from the preliminary testing phase allow investigating the influence of the core soft layer type on the specimen response, cf. Tables 4 and 7. It can be seen that the effect of the core layer type on the stiffness, apparent yield displacement and the horizontal force resistance of the specimens with a multi-layer bed joint is almost negligible. On the other hand, the deformation capacity of the tested specimens exhibits some variability. Considering the intended purpose of a multi-layer bed joint to modify the seismic response of URM walls, it can be concluded that the smallest benefits are obtained when using a cork core soft layer (Specimen WK), since the ultimate horizontal displacement is significantly smaller than that of the other specimens. For Specimens WGK and WK, the crack pattern, characteristic for the walls failing in shear, started developing at an early stage in the tests causing degradation of both the horizontal force resistance and the stiffness, cf. Fig. 7. Specimens WG and WB exhibited more favourable behaviour, albeit with different levels of core soft layer damage. Finally, the rubber granulate core soft layer was chosen for the main testing phase, since it exhibited a higher durability under repeated cycles than the bitumen core soft layer. 


\subsection{Soft layer degradation}

Figs. 18 and 19 show the layers (elastomer and core soft layers) of the multi-layer bed joints after testing in both the preliminary and the main phases, respectively. As can be seen, there was almost no degradation of the core soft layers of Specimens WG, WGK and WK. Only local damage to the core soft layers and elastomer was detected at the location where the tensile cracks in the bottom brick course appeared. However, the bitumen based core soft layer (Specimen WB) underwent considerable damage during cycling and became stuck to the sheets of the elastomer, cf. Fig. 18. For the main phase full-scale specimens, which were tested at the higher levels of pre-compression, a soft layer degradation depended on the extent of sliding motion: the smaller the sliding motion (e.g. relatively early shear failure of Specimens Z3 and Z5), the less the degradation of soft layers. An extensive sliding motion of Specimen Z2 caused only wrinkling deformation at the outer edges of the elastomer layers. However, in the case of Specimens Z1 and Z6 (both developed reduced effective areas), local damage to the rubber granulate core soft layer, i.e. crumbling caused by normal stress concentration in combination with the sliding motion, was detected at the location of the tensile cracks in the bottom brick course. Moreover, the elastomer layers suffered tensile cracks (rupture) at the same position, cf. Fig. 19. The abraded surface of the elastomer sheets, observed in all specimens, clearly indicated the pronounced sliding at the interface between the elastomer and the core soft layer. Finally, the installed protective extruded elastomer layers were able to limit the deterioration of all core soft layers, except for the bitumen layer.

\section{Summary and conclusions}

The results from two testing phases on URM walls with multi-layer bed joints were presented and discussed. Multi-layer bottom bed joints, placed between the floor and the first masonry brick course, comprise a core soft layer placed between two protective layers of extruded elastomer. All specimens with a rubber granulate core soft layer, which has been chosen as 
the best of four considered core soft layer types based on the results of the preliminary testing phase, responded in the same manner, i.e. the initial shear deformation of the core soft layer was followed by sliding along the core soft layer. Thus, the horizontal force resistance can be predicted adequately using the Mohr-Coulomb friction law. Based on the presented test results, an apparent friction coefficient of 0.2 and the corresponding apparent cohesion of 0.15 $\mathrm{MPa}$, are recommended to estimate the horizontal force resistance of full-scale URM walls with rubber granulate multi-layer bed joints. Further, an equation for calculating the initial elastic stiffness, which considers the shear deformation of the multi-layer bed joint as well the influence of the wall pre-compression, is proposed. The extent of shear cracks developed in the wall as well as the appearance of (vertical) tensile cracks, which reduced the effective area of the walls, strongly influenced the failure mode and the ultimate displacement capacity of the tested walls.

A method to construct an idealization of the horizontal force-displacement response envelope for the tested URM walls with multi-layer bed joints is proposed. The parameters of this envelope are defined by analogy to the response envelope proposed in FEMA-356 [24] to capture the strength, stiffness and ultimate displacement capacity of the walls, as well as to model sudden drops in wall horizontal force resistance if they occur.

The presence of a multi-layer bed joint with a rubber granulate core soft layer results in relatively soft response of URM walls, i.e. leads to an elongation of the initial fundamental vibration period of URM structures that contain such multi-layer bed joints. Further, the multi-layer bed joints can allow for a remarkable amount of plastic deformation (given their thickness) before the onset of shear failure (if any) of the masonry, making their response quasi-ductile. Therefore, multi-layer bed joints in URM walls act to modify the dynamic response of structures and improve their seismic performance. The displacement capacities of URM walls with multi-layer bed joints are, however, relatively small, making this response modification approach suitable for regions of low and moderate seismicity. 
Additional research is ongoing in two important areas. First, analytical and numerical models of URM walls with multi-layer bed joints is needed to simulate the dynamic response of structures with such walls to earthquake ground motion excitation. Such models must appropriately reflect the sensitivity of the core soft layers to the velocity of the motion. Further, such models should encompass both in-plane and out-of-plane response. Second, more tests are needed to classify the seismic performance of URM walls with multi-layer bed joints, particularly to combined in- and out-of-plane loading.

\section{Acknowledgments}

Funding from the Swiss National Science Foundation (Grant 200021_146417) is gratefully acknowledged. The soft layer membranes were supplied free of charge by HBT-ISOL AG and Pronouvo AG. Mr. Joseph Ronner and Mr. Felix Walker from ZZ Wancor AG assisted in preparing the specimens. This support is also gratefully acknowledged.

\section{References}

[1] Ueda N, Onishi A, Shimizu M. Sanjusangen-do. 2004, accessed 15 September 2016 http://thekyotoproject.org/english/sanjusangen-do/

[2] Joshi RN. Striking behavior of structures in Assam earthquakes. In: Proceedings of the $2^{\text {nd }}$ World Conference on Earthquake Engineering, Tokyo; 1964, vol. 3. p. 2143-58.

[3] Arya AS, Qamaruddin M, Chandra B. A new system of brick buildings for improved behavior during earthquakes. In: Proceedings of the $7^{\text {th }}$ World Conference on Earthquake Engineering, Istanbul; 1980, vol. 4. p. 225-32.

[4] Qamaruddin M, Arya AS, Chandra B. Dynamic testing of brick building models. In: Proceedings of the Institution of Civil Engineers, London; 1984, vol. 77(3). p. 353-365.

[5] Lou Y, Wang M, Su Z. Research of Sliding Shock Absorbing of Multistory Brick Buildings. In: Proceedings of the 10th World Conference on Earthquake Engineering, Madrid; 1992, vol. 4. p. 2499-2504.

[6] Nikolic-Brzev S, Arya AS. Seismic isolation of masonry buildings - An experimental study. In: Proceedings of the $11^{\text {th }}$ World Conference on Earthquake Engineering, Acapulco; 1996 [paper no. 559].

[7] Nanda RP, Agarwal P, Shrikhande M. Friction base isolation by geotextiles for brick masonry buildings. Geosynthetics International 2010:17(1):48-55. 
[8] Nanda RP, Agarwal P, Shrikhande M. Suitable friction sliding materials for base isolation of masonry buildings. Journal of Shock and Vibration 2012:19(6):1327-1339.

[9] Petrović M, Mojsilović N, Stojadinović B. Use of soft layers to modify the response of masonry structures: State-of-the-art review. In: Proceedings of the $12^{\text {th }}$ North American Masonry Conference, Denver; 2015. [10] Mojsilović N, Stojadinović B, Barandun A, Vögeli C. Seismic behavior of masonry walls with soft-layer wall bearings. In: Proceedings of the $5^{\text {th }}$ International Conference on Structural Engineering, Mechanics and Computation, Cape Town; 2013, p. 1865-70.

[11] Vögeli C, Mojsilović N, Stojadinović B. Masonry wallettes with a soft layer bed joint: Behaviour under static-cyclic loading. Engineering Structures 2015:86:16-32.

[12] Mojsilović N, Petrović M, Anglada XR. Masonry elements with multi-layer bed joints: Behaviour under monotonic and static-cyclic shear. Construction and Building Materials 2015:100:149-162.

[13] Trajkovski S, Totoev YZ. Shear strength of masonry including damp proof course: experimental determination at different strain rates. In: Proceedings of the $6^{\text {th }}$ International Masonry Symposium, London; 2002, p. 487-492.

[14] Petrović M, Mojsilović N, Stojadinović B. Masonry walls with a multi-layer bottom bed joint: Behavior under static-cyclic shear. In: Proceedings of the $11^{\text {th }} \mathrm{PhD}$ International Symposium in Civil Engineering, Tokyo; 2016, p. 687-694.

[15] EN 772-1:2011. Methods of test for masonry units, Part 1: Determination of compressive strength. European Committee for Standardization (CEN), Brussels; 2011.

[16] EN 1015-11:1999. Methods of test for mortar for masonry, Part 11: Determination of flexural and compressive strength of hardened mortar. European Committee for Standardization (CEN), Brussels; 1999.

[17] EN 1052-1:1998. Methods of test for masonry, Part 1: Determination of compressive strength. European Committee for Standardization (CEN), Brussels; 1998.

[18] Mojsilović N, Petrović M, Büchler R. Compressive strength of masonry with soft layers in bed joint. In: Proceedings of the $6^{\text {th }}$ International Conference on Structural Engineering, Mechanics and Computation, Cape Town; 2016, p. 1691-96.

[19] Salmanpour AH, Mojsilović N. Simulation of Boundary Conditions for Testing of Masonry Shear Walls. In: Proceedings of the International Conference of Computational Methods in Sciences and Engineering, Athens; 2015.

[20] Salmanpour AH, Mojsilović N, Schwartz J. Displacement capacity of contemporary unreinforced masonry walls: An experimental study. Engineering Structures 2015:89:1-16. 
[21] Salmanpour AH, Mojsilović N. Application of Digital Image Correlation for strain measurements of large masonry walls. In: Proceedings of the $5^{\text {th }}$ Asia Pacific Congress on Computational Mechanics, Singapore; 2013. [22] Mojsilović N, Salmanpour AH. Masonry walls subjected to in-plane cyclic loading: Application of Digital Image Correlation for deformation field measurement. Int. J. of Masonry Research and Innovation 2016:1(2):165-187.

[23] Chopra AK. Dynamics of Structures: Theory and Applications to Earthquake Engineering. New Jersey: Prentice Hall; 2012.

[24] FEMA 356. Prestandard and commentary for the seismic rehabilitation of buildings. Federal Emergency Management Agency (FEMA), Washington; 2000.

[25] Tomaževič M. Earthquake-resistant design of masonry buildings. London: Imperial College Press; 1999. [26] Assessment and improvement of the structural performance of the buildings in earthquakes. New Zealand Society for Earthquake Engineering (NZSEE), Wellington; 2006. 


\section{Figure captions}

Fig. 1: Specimen layout and materials

Fig. 2: Test set-up

Fig. 3: Instrumentation plan

Fig. 4: Implemented 2D-DIC measurement system: a) global (East face); b) local (West face)

Fig. 5: Specimen WK: a) applied pattern; b) major principal strain field at the target displacement of $3.2 \mathrm{~mm}$; c) local shear strain field at the target displacement of $0.4 \mathrm{~mm}$ Fig. 6: Specimen Z3: a) applied pattern; b) major principal strain field at the target displacement of $5.2 \mathrm{~mm}$; c) minor principal strain field

Fig. 7: Horizontal force-displacement response hysteresis curves for both testing phases Fig. 8: Equivalent viscous damping ratio: a) preliminary testing phase; b) main testing phase Fig. 9: Failure modes of selected specimens from the first testing phase series: a) sliding in the multi-layer bed joint of specimen WGK; b) reduced wall effective area of specimen WG; c) reduced wall's effective area of specimen WB

Fig. 10: Final crack patterns for the specimens in the preliminary testing phase

Fig. 11: Final crack patterns for specimens Z1, Z2 and Z3

Fig. 12: Final crack patterns for specimens Z5 and Z6

Fig. 13: Mohr-Coulomb failure criterion: a) shear vs. normal stress for specimens Z1, Z2 and $\mathrm{Z3}$; b) correlation between the measured and the calculated values of the horizontal force resistance

Fig. 14: Tangent stiffness vs. calculated elastic stiffness for all specimens

Fig. 15: Idealization of the horizontal force-displacement hysteretic response: a) multilinear; b) bilinear

Fig. 16: Measured vs. idealized horizontal force-displacement hysteretic response: a) Specimen Z6; b) Specimen Z1 
Fig. 17: Idealized horizontal force-displacement response: a) preliminary testing phase; b) main testing phase

Fig. 18: Degradation of the soft layers: preliminary testing phase

Fig. 19: Degradation of the soft layers: main testing phase 
Table 1. Testing programme and specimen designation

\begin{tabular}{|c|c|c|c|c|c|c|}
\hline Phase & Specimen & Core soft layer & $t_{c s l}[\mathrm{~mm}]$ & $\begin{array}{l}\text { Dimensions } \\
l_{w} \times h_{w} \times t_{w}[\mathrm{~mm}]\end{array}$ & Aspect ratio & $\sigma_{p c} / f_{x}$ \\
\hline Preliminary & WG & Rubber granulate & 3 & $1500 \times 1600 \times 150$ & 0.94 & 0.10 \\
\hline Preliminary & WGK & Cork-rubber granulate & 3.2 & $1500 \times 1600 \times 150$ & 0.94 & 0.10 \\
\hline Preliminary & WK & Cork & 3.5 & $1500 \times 1600 \times 150$ & 0.94 & 0.10 \\
\hline Preliminary & WB & Bitumen & 2 & $1500 \times 1600 \times 150$ & 0.94 & 0.10 \\
\hline Main & $\mathrm{Z1}$ & Rubber granulate & 3 & $2700 \times 2600 \times 150$ & 1.04 & 0.10 \\
\hline Main & $\mathrm{Z} 2$ & Rubber granulate & 3 & $2700 \times 2600 \times 150$ & 1.04 & 0.05 \\
\hline Main & $\mathrm{Z3}$ & Rubber granulate & 3 & $2700 \times 2600 \times 150$ & 1.04 & 0.20 \\
\hline Main & $\mathrm{Z5}$ & Rubber granulate & 3 & $1800 \times 2600 \times 150$ & 0.69 & 0.10 \\
\hline Main & Z6 & Rubber granulate & 3 & $3600 \times 2600 \times 150$ & 1.38 & 0.10 \\
\hline
\end{tabular}

Table 2. Masonry compressive strength

\begin{tabular}{lll}
\hline Core soft layer & $f_{x}[\mathrm{MPa}]$ & $\beta$ \\
\hline- & 5.18 & 1 \\
Rubber granulate & 4.61 & 0.89 \\
Cork-rubber granulate & 5.26 & 1.02 \\
Cork & 5.01 & 0.97 \\
Bitumen & 5.13 & 0.99 \\
\hline
\end{tabular}




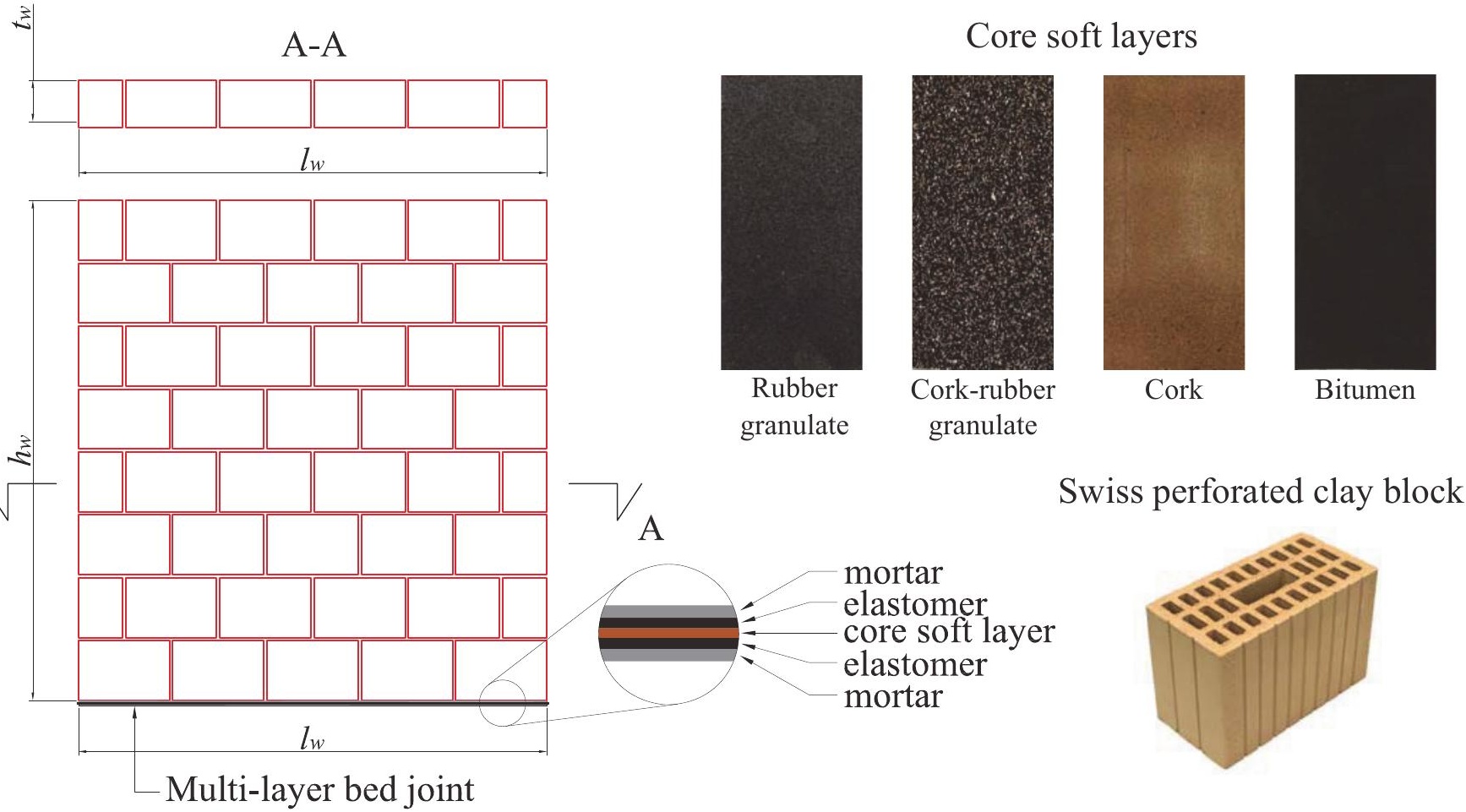



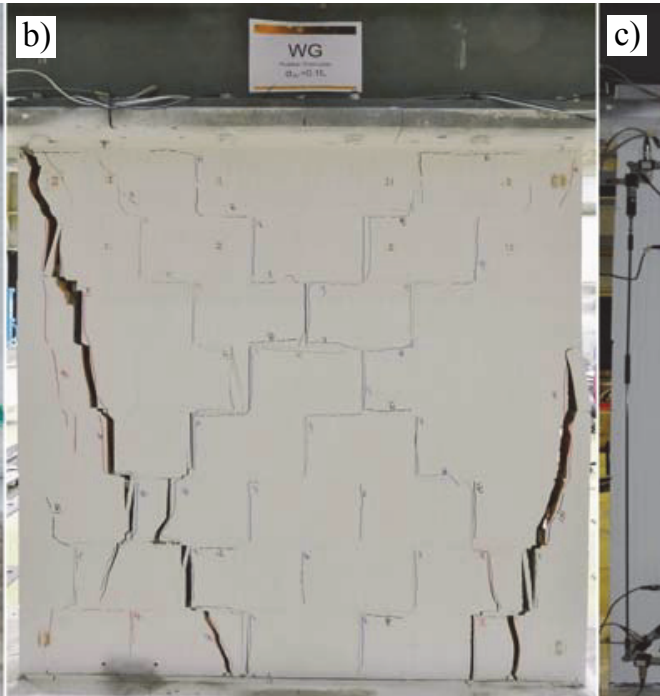

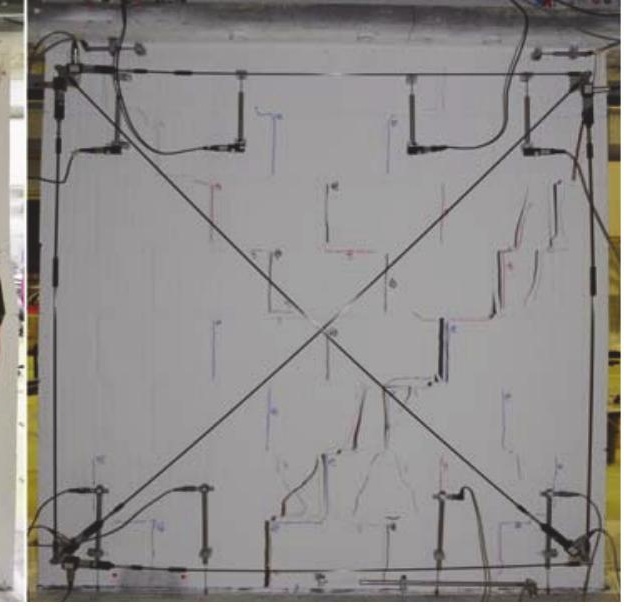

.

.
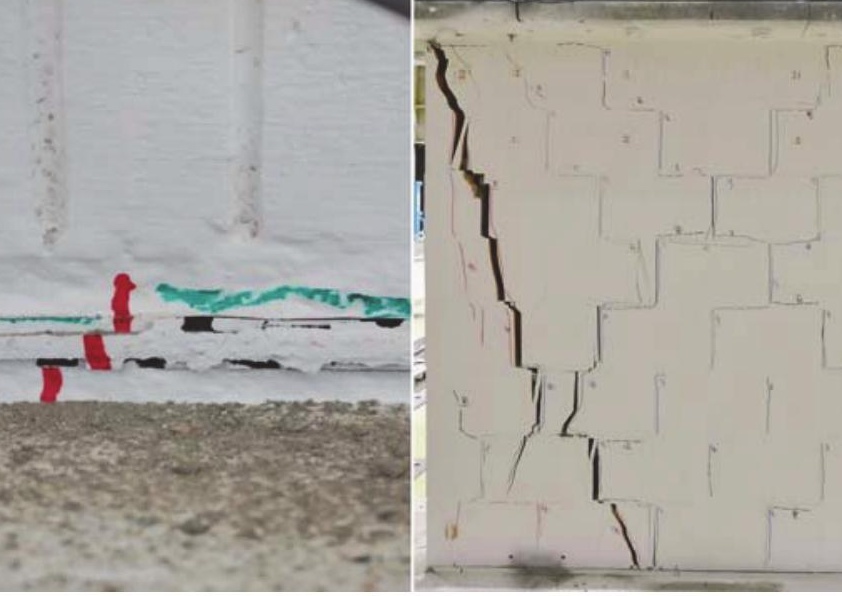
a)

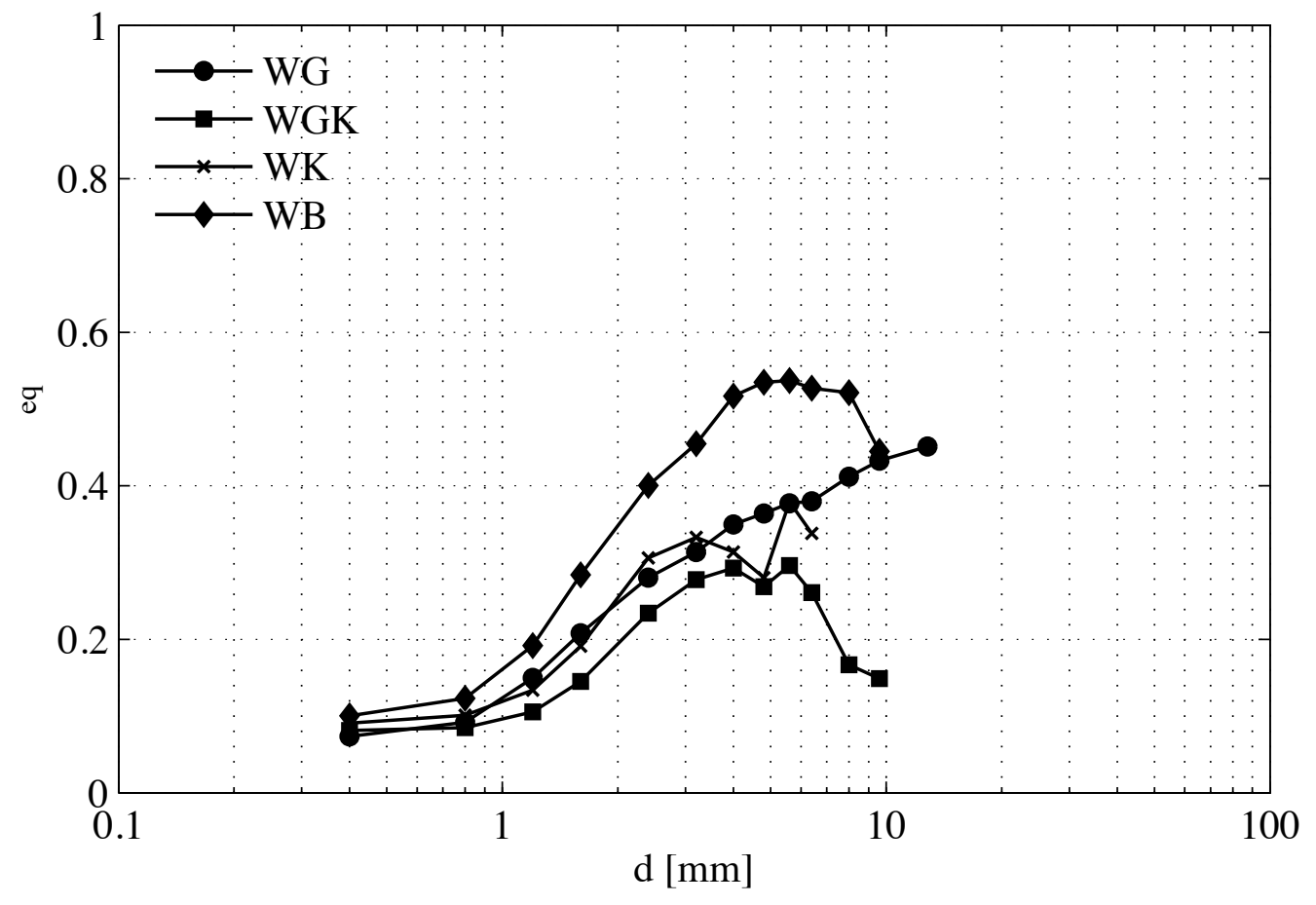

b)

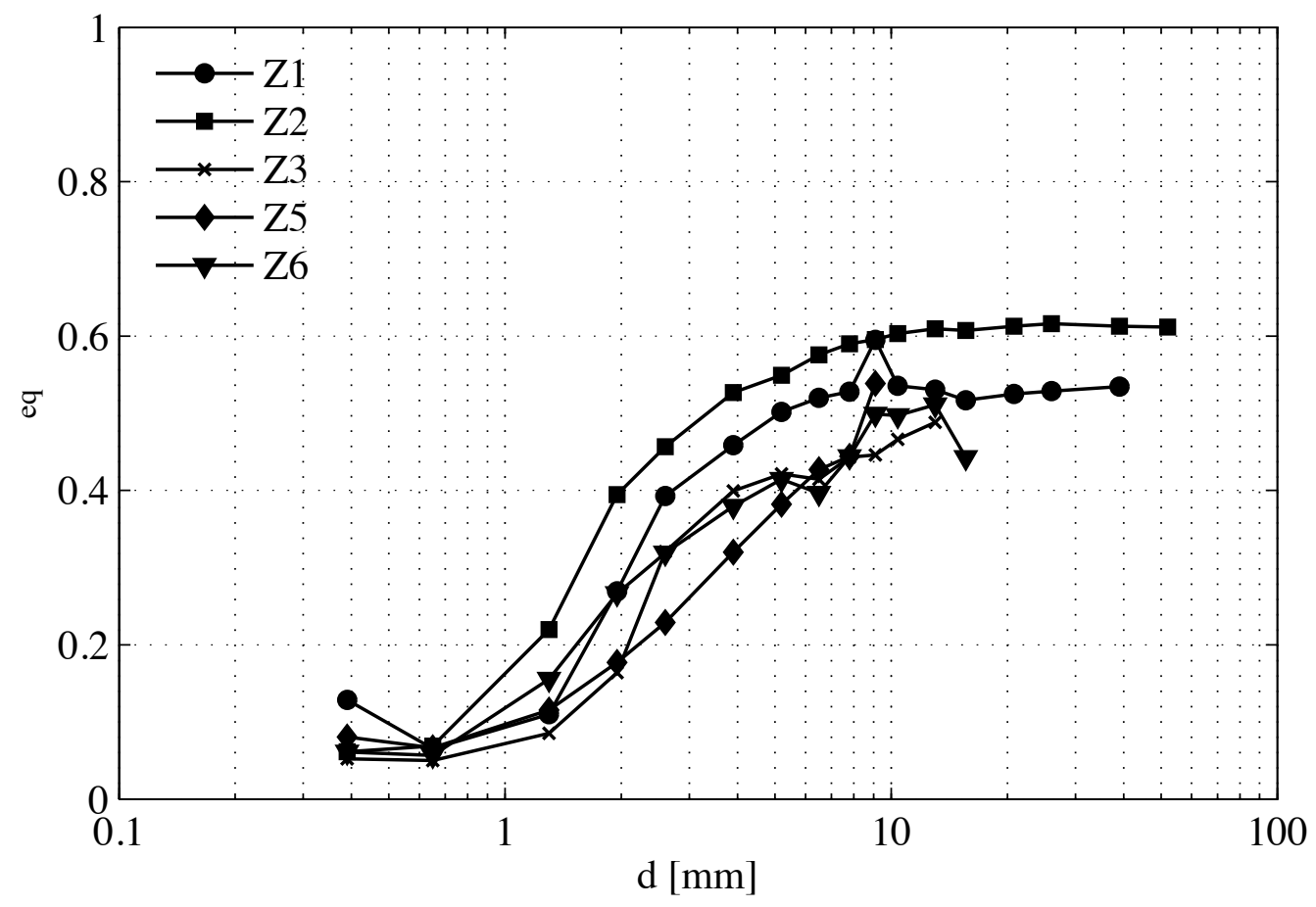




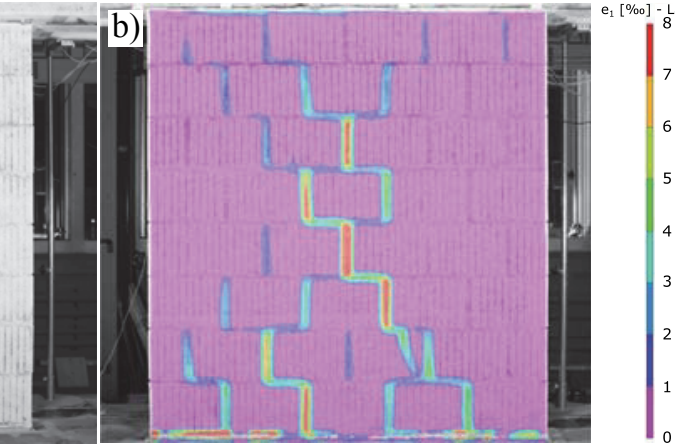

c) sit n.

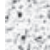

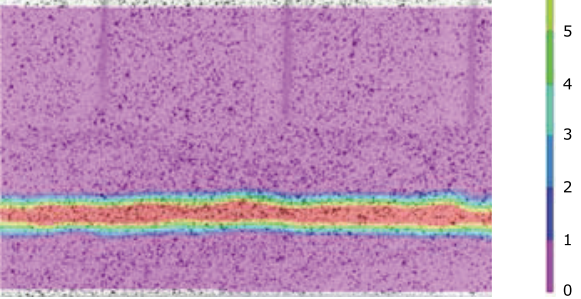
5
4
3
2
1
0 


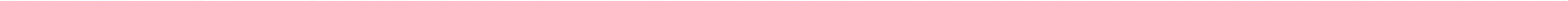




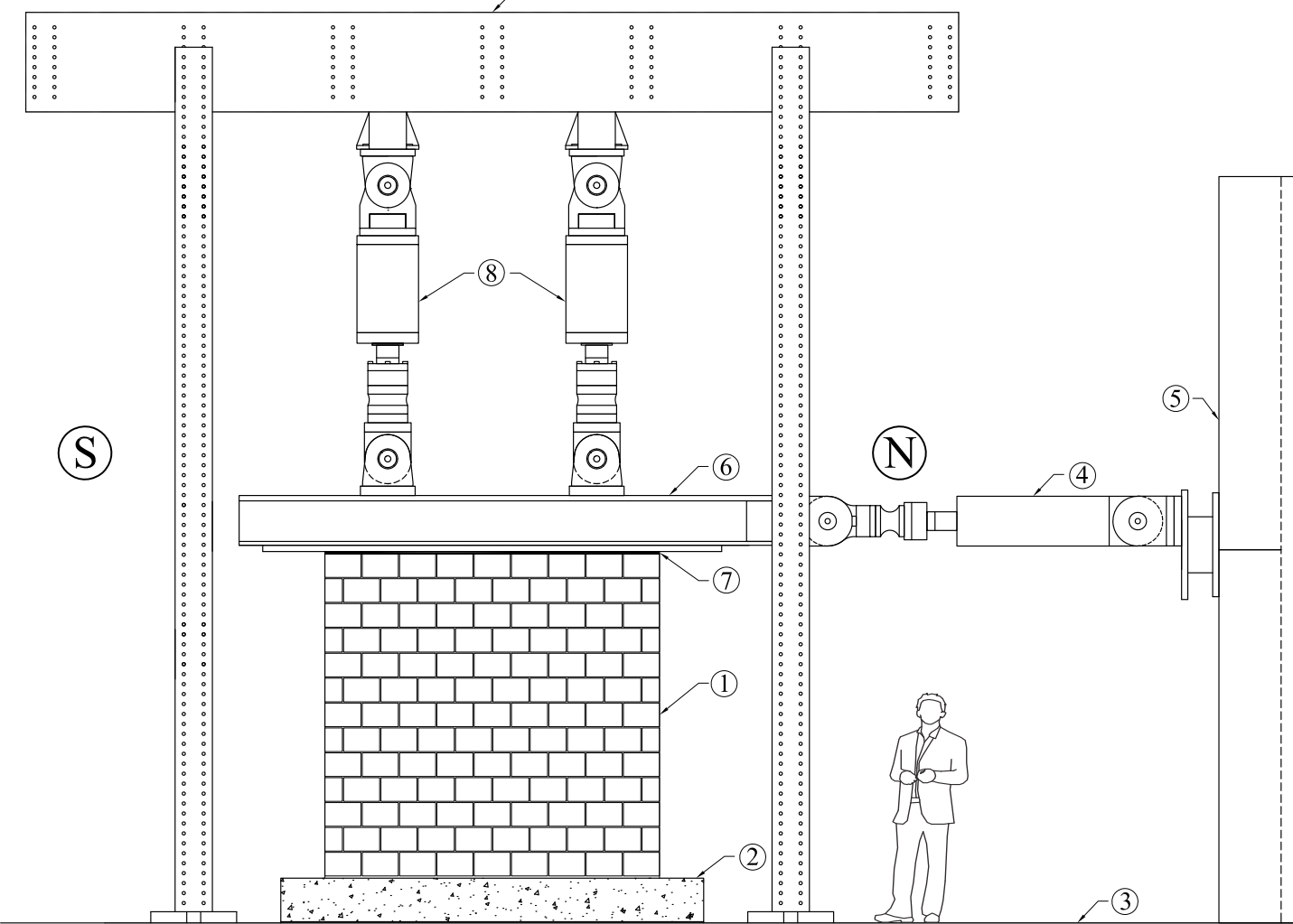




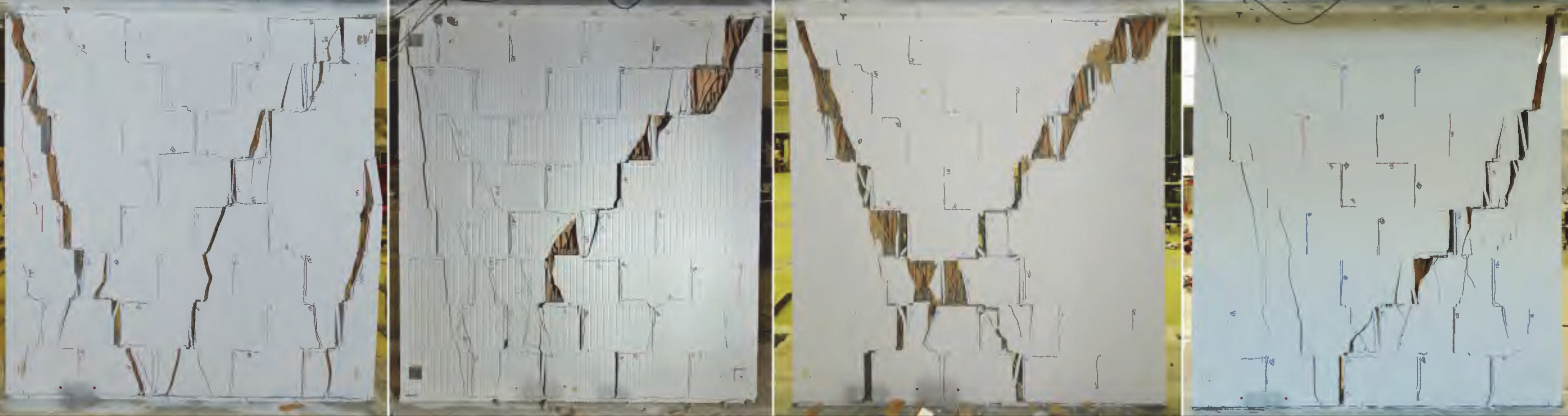


$\mathrm{Z1}$

$Z 1$

menam

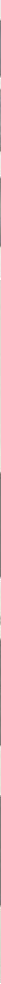


a)

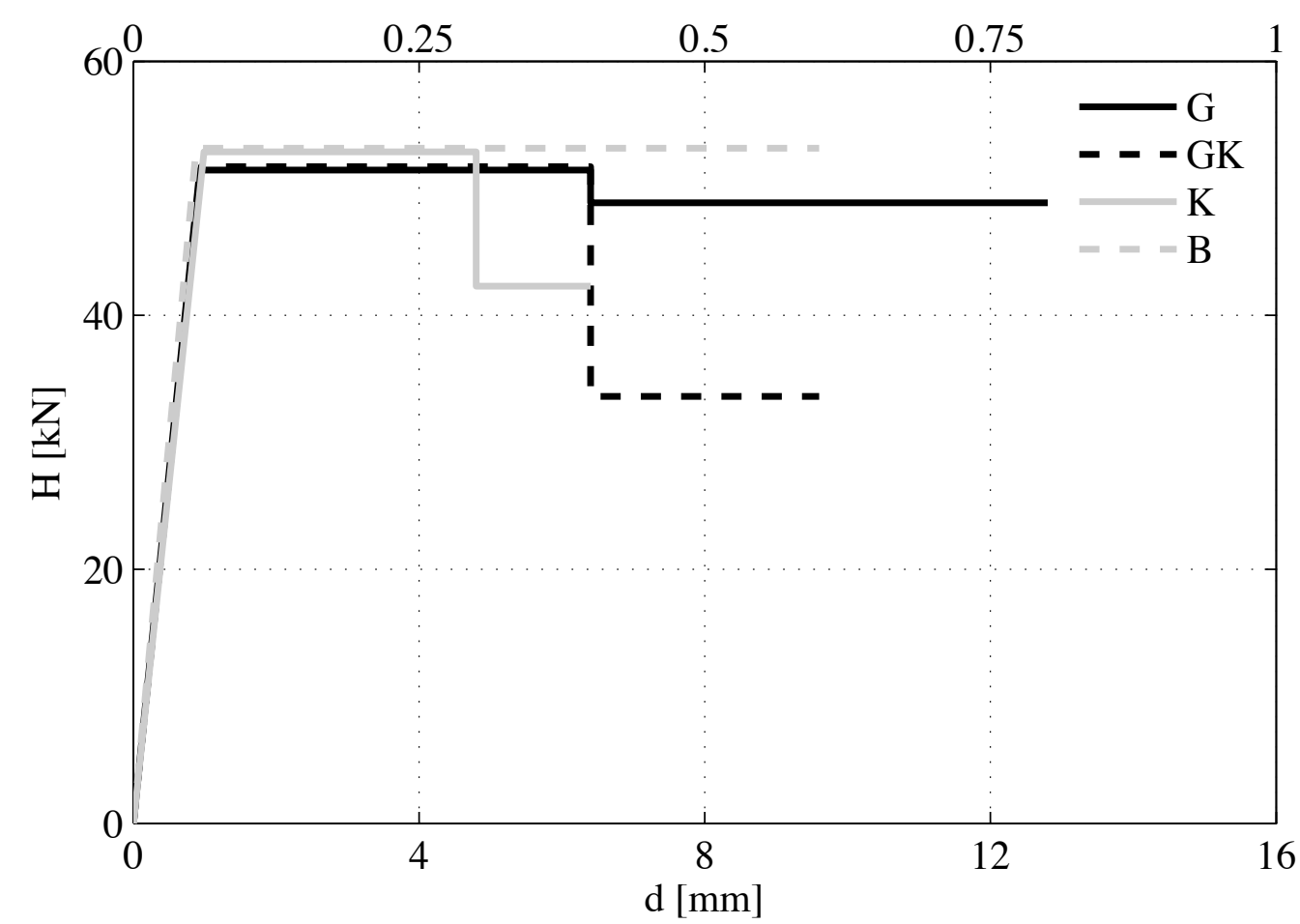

b)

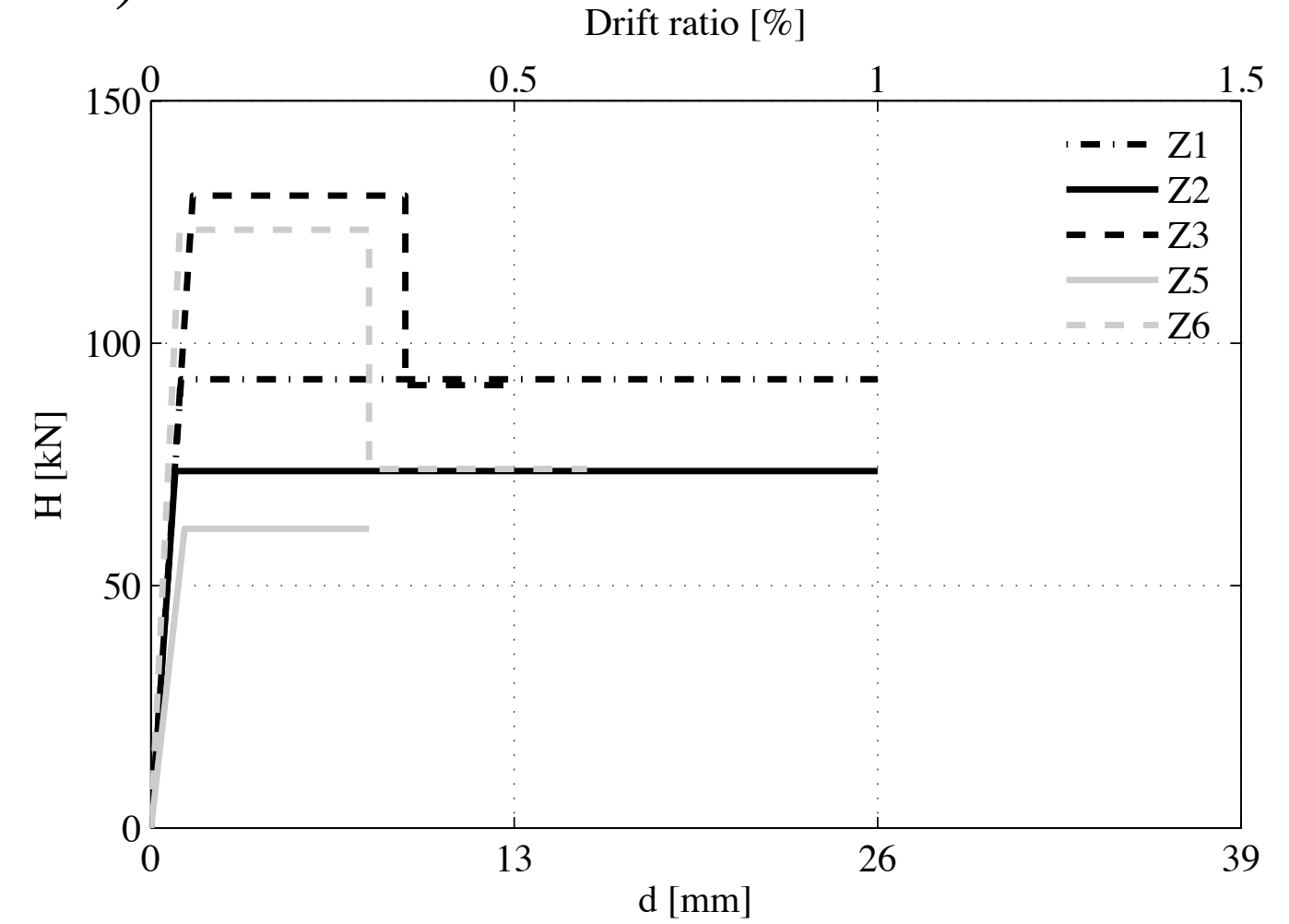


b)
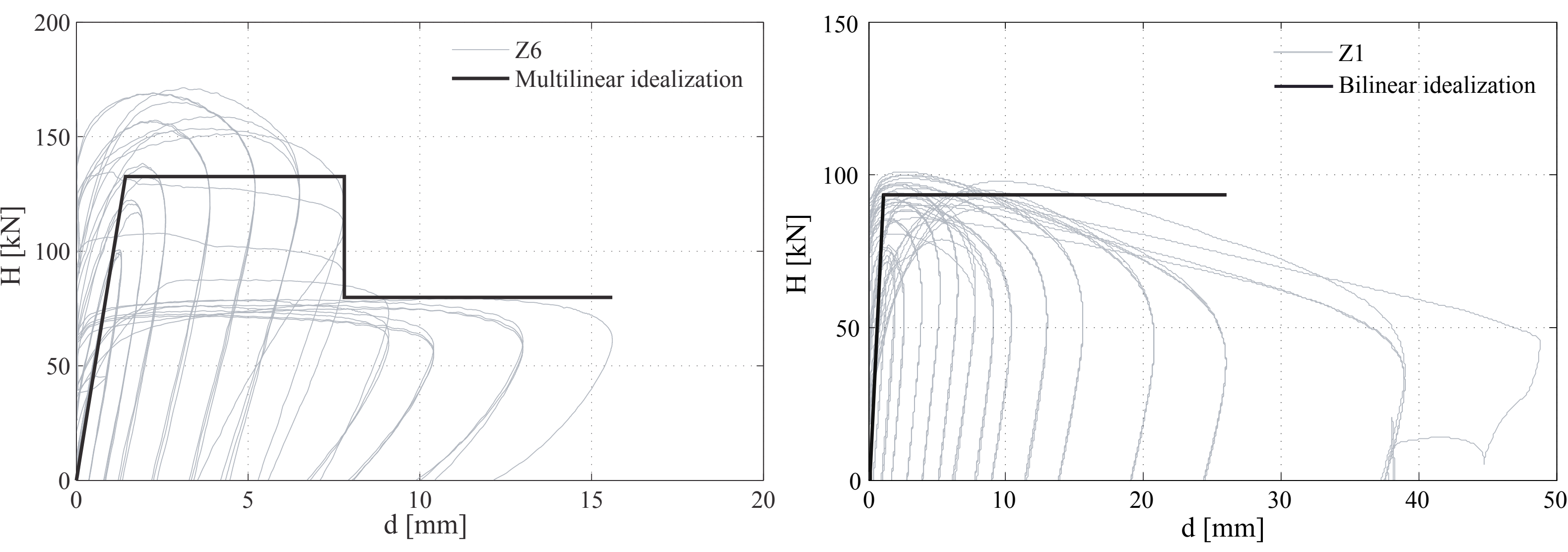


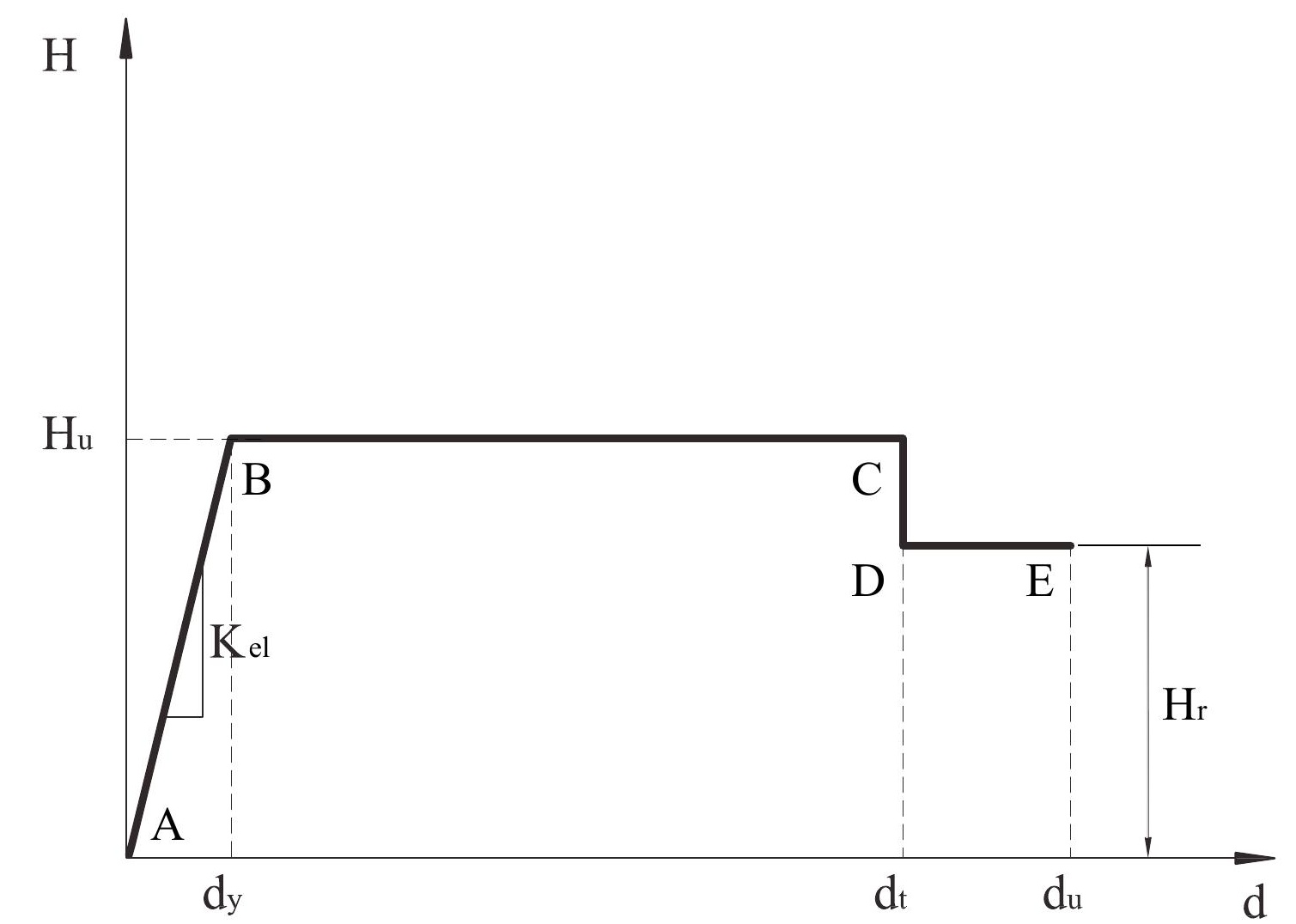

$\mathrm{H}$

$\mathrm{Hu}$

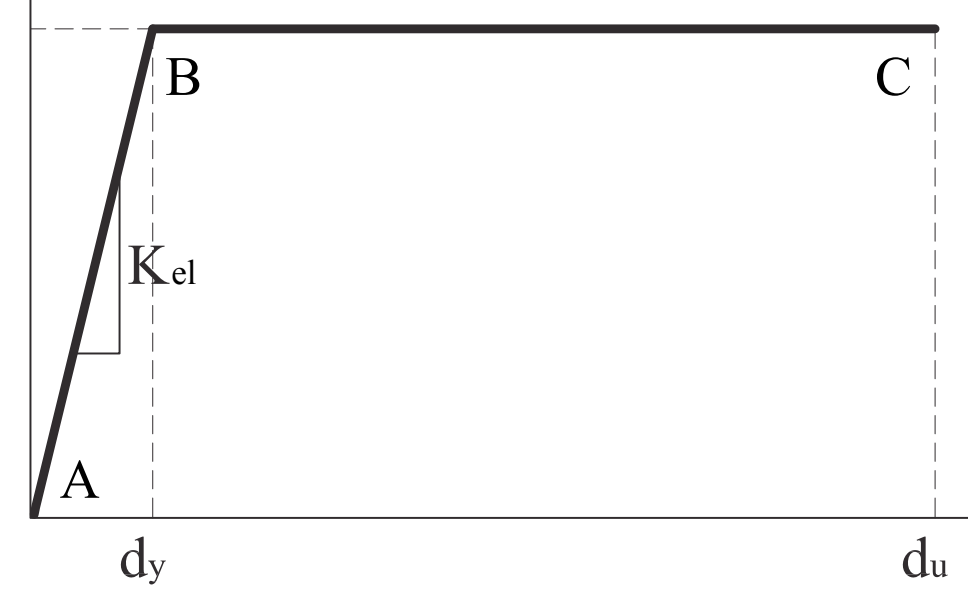




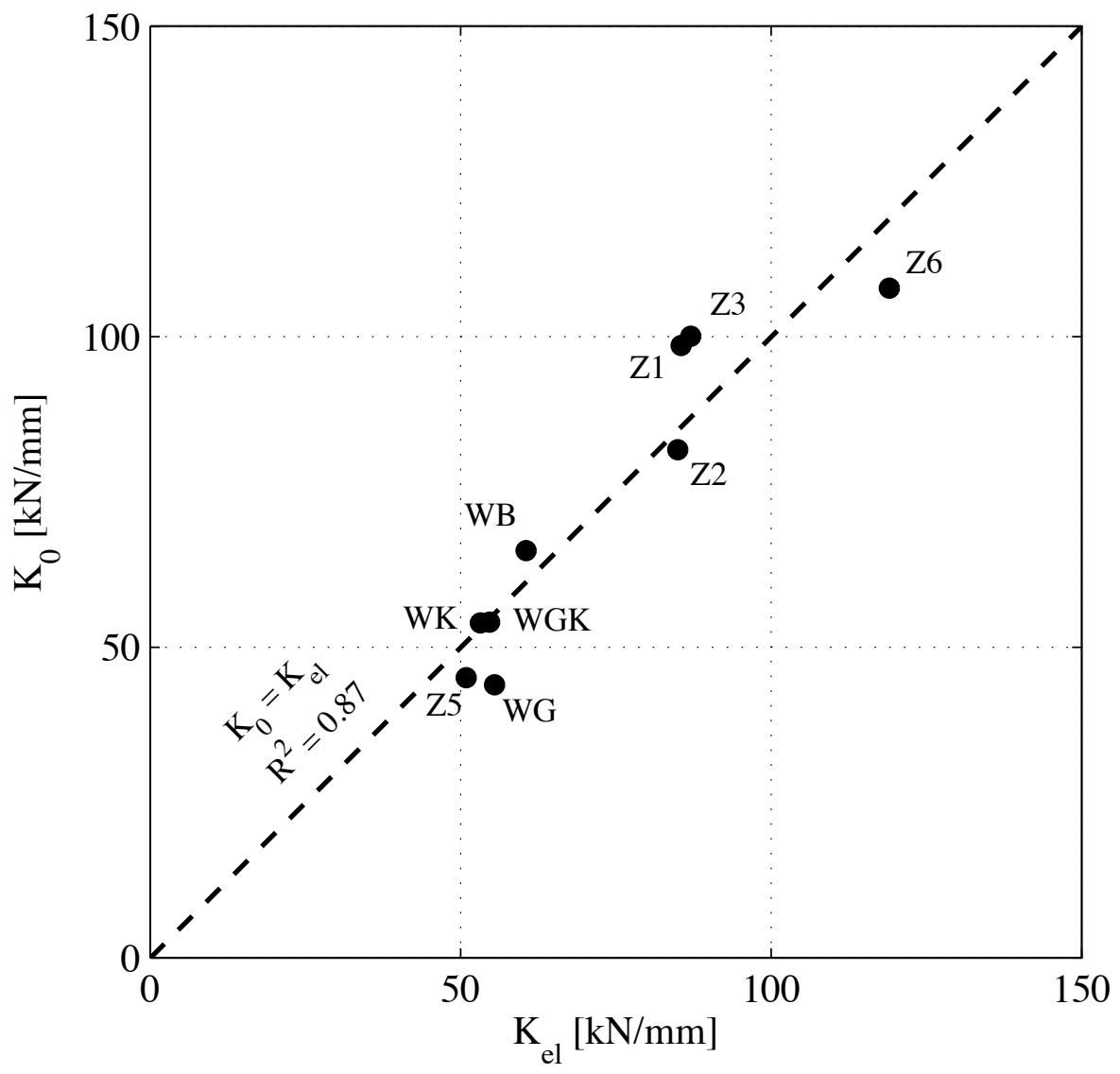


a)

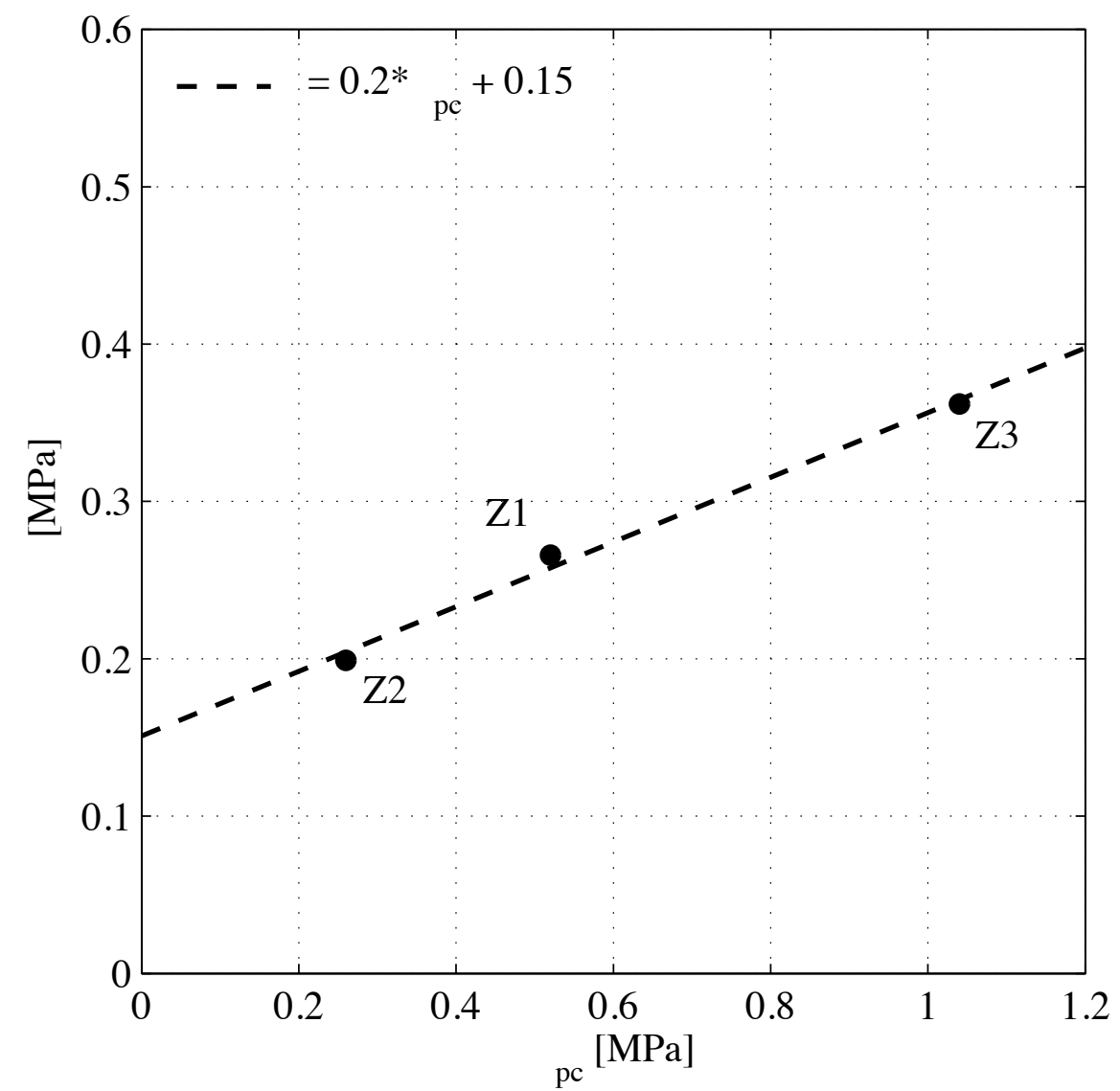

b)

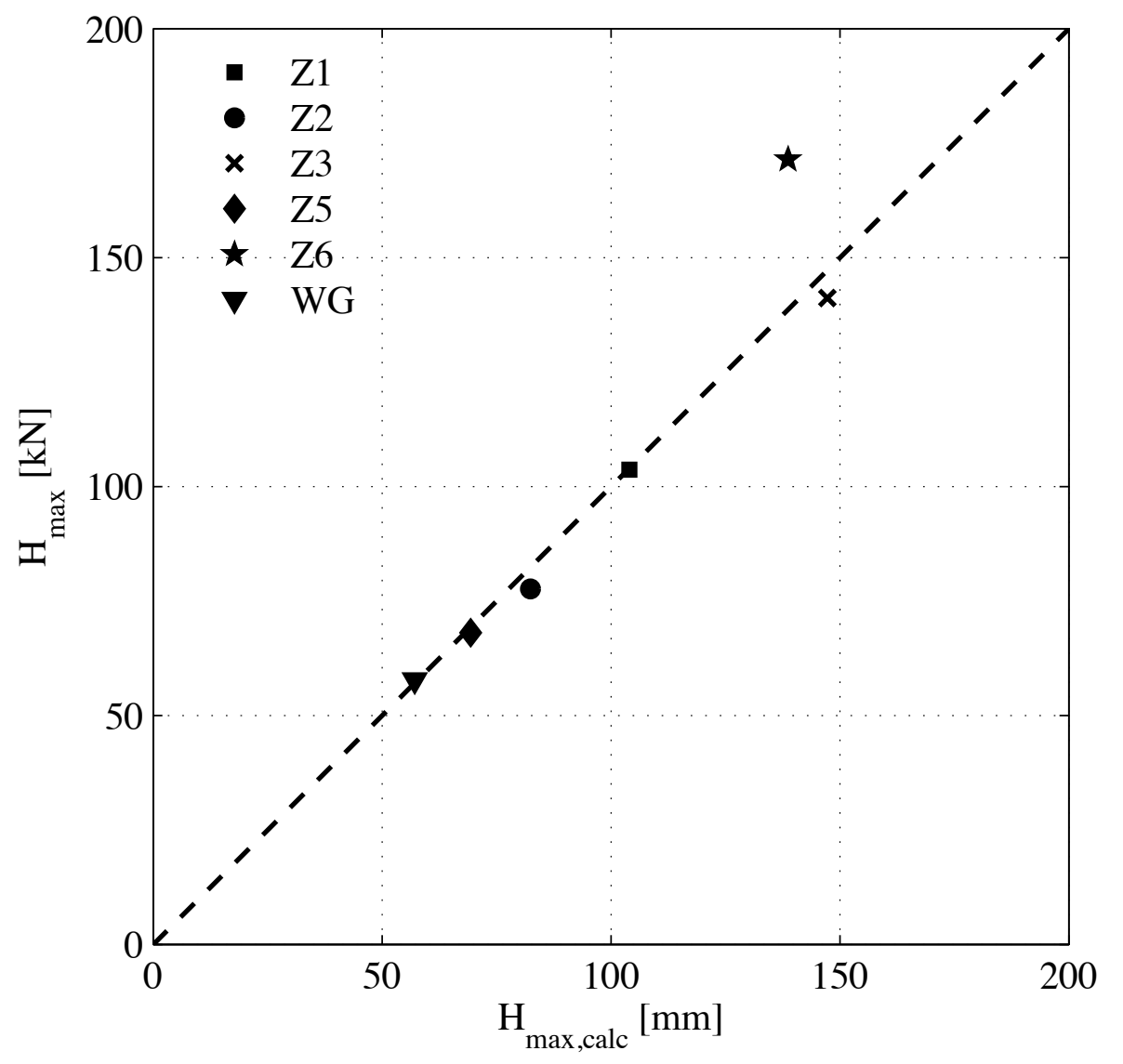




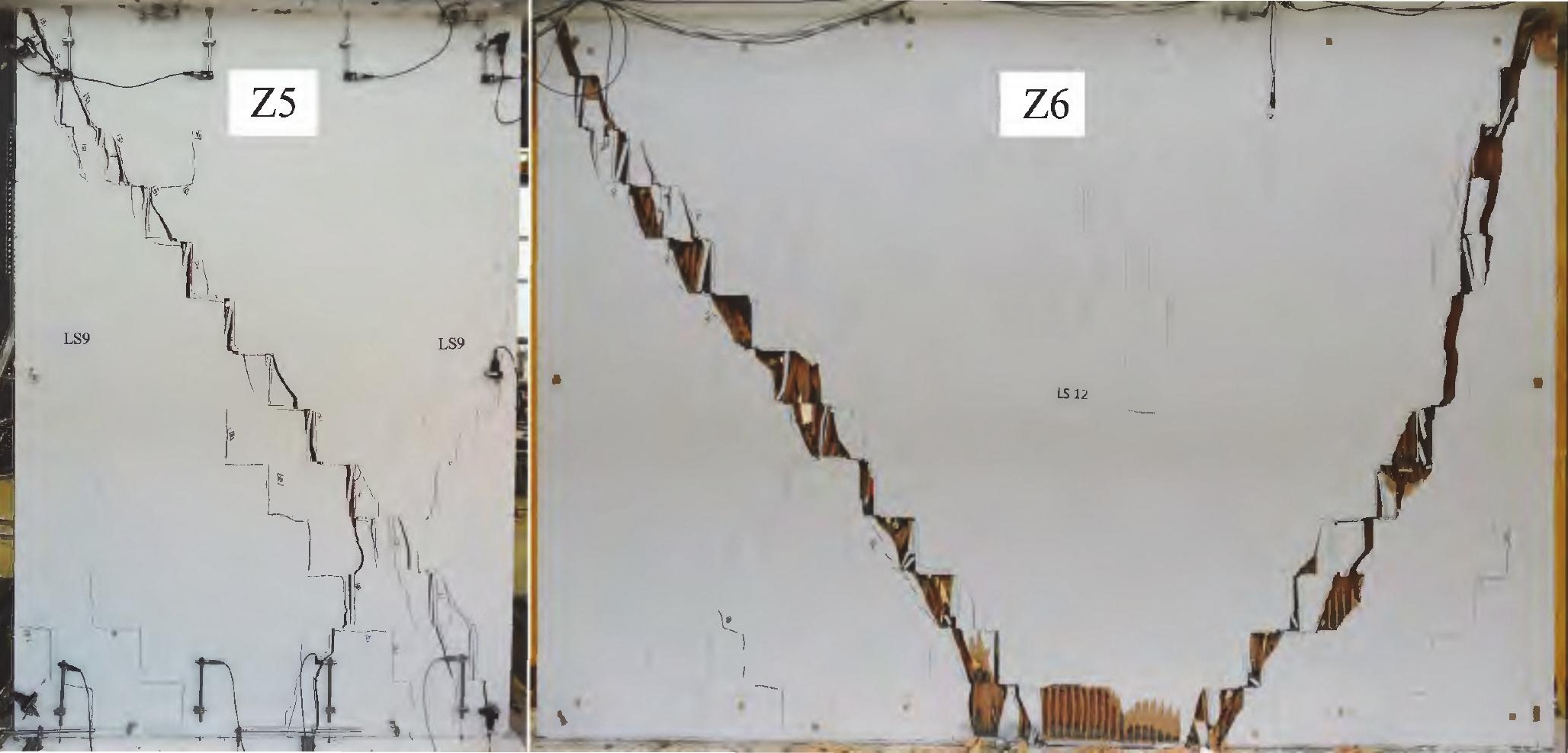




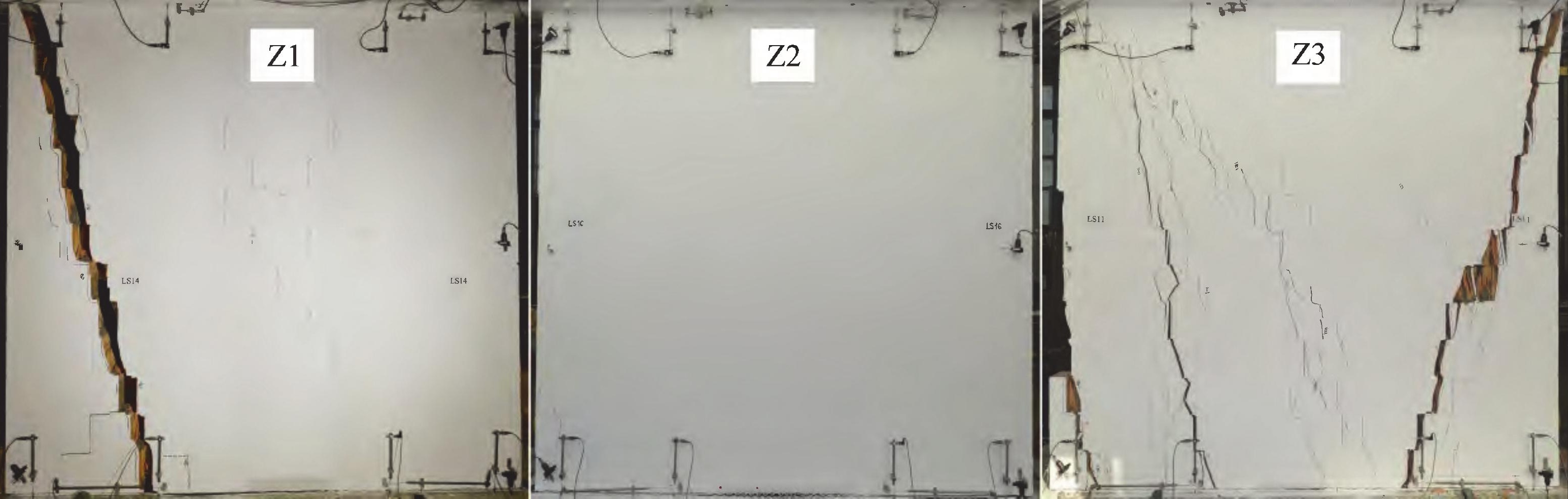

